\title{
ABO-incompatible living donor liver transplantation with a simplified desensitization and immunosuppression protocol: a single center retrospective study
}

\author{
Tae Beom Lee, Hyojeong Ko, Jae Ryong Shim, Byung Hyun Choi, Kwangho Yang, Je Ho Ryu
}

Department of Surgery-Hepatobiliary, Pusan National University Yangsan Hospital, Yangsan, Korea

Background: New desensitization strategies have made ABO-incompatible living donor liver transplantation an attractive option for patients with end-stage liver disease. We aimed to report our experience with 20 consecutive patients who underwent ABO-incompatible living donor liver transplantation using a simple $A 1$ desensitization and immunosuppression regimen.

Methods: We retrospectively analyzed 20 ABO-incompatible living donor liver transplantation cases (August 2015 to July 2019). The ABO-incompatible living donor liver transplantation protocol involved rituximab administration $\left(375 \mathrm{mg} / \mathrm{m}^{2}\right.$ body surface area) at 2-3 weeks preoperatively, subsequent plasma exchanges (target isoagglutinin titer: $\leq 1: 8)$, basiliximab administration (20 $\mathrm{mg}$ on the day of surgery and postoperative day 4$)$, and intravenous immunoglobulin administration $(2 \mathrm{~g} /$ day from the day of surgery to postoperative day 7). No graft local infusion therapy or splenectomy was performed.

Results: Living donor liver transplantation involved a modified right lobe graft for 18 patients and a right posterior segment graft for one patient. The most common reason for liver transplantation was hepatitis B virus-associated liver cirrhosis (16 patients), and 14 patients had hepatocellular carcinoma. The mean age was $55.4 \pm 6.3$ years, mean model end-stage liver disease score was $14.7 \pm 7.7$, and mean graft-to-recipient weight ratio was $1.07 \% \pm 0.2 \%$. The median initial anti-ABO antibody titers were $1: 16$ for immunoglobulin $\mathrm{M}$ (range, 1:2-1:256) and 1:48 for immunoglobulin $\mathrm{G}$ (range, 1:4-1:>2,048). The median number of plasma exchanges was 2 (range, 0-12). No cases involved biopsy-confirmed antibody-mediated rejection. No bacterial or fungal infections were observed. Biliary anastomotic stricture was observed in nine cases.

Conclusions: This ABO-incompatible living donor liver transplantation protocol with rituximab, plasma exchange, low-dose intravenous immunoglobulin, and immunosuppression (equivalent to $\mathrm{ABO}$-compatible living donor liver transplantation) could be a safe and effective way to overcome antibody-mediated rejection and other complications.

Corresponding author: Je Ho Ryu

E-mail: ryujhhim@hanmail.net

(C) The Korean Society for Transplantation

This is an Open Access article distributed under the terms of the Creative Commons Attribution Non-Commercial License (http://creativecommons.org/licenses/by-nc/4.0/) which permits unrestricted non-commercial use, distribution, and reproduction in any medium, provided the original work is properly cited. 